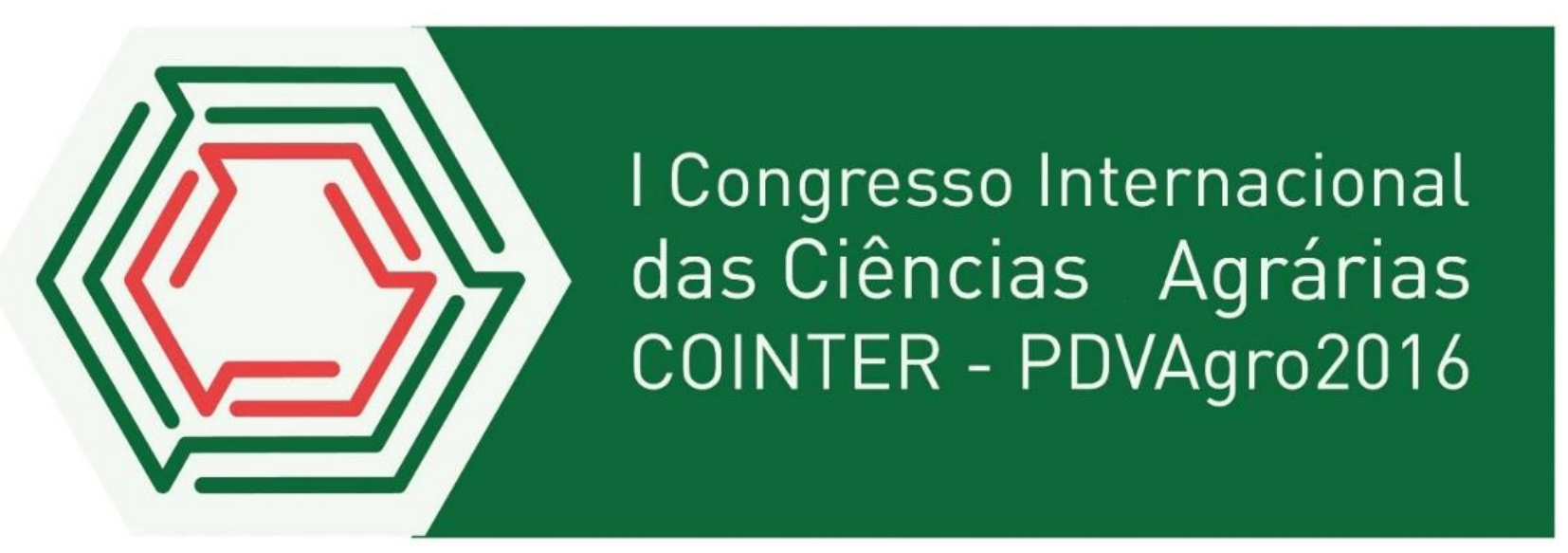

\title{
APLICAÇÃO DO DIAGNÓSTICO RÁPIDO PARTICIPATIVO NA COMUNIDADE DE QUEIMADOS, FEIRA NOVA- PE
}

\author{
Apresentação: Comunicação Oral \\ Adjair José da Silva ${ }^{1}$; José Denilson da Silva² ${ }^{2}$ Ronaldo Alves de Oliveira Filho ${ }^{3}$
}

\section{Resumo}

Este trabalho tem como objetivo a aplicação de técnicas de Diagnóstico Rural Participativo (DRP). Com o levantamento de dados através de aplicação de questionários, visando na melhoria no processo produtivo agrícola na comunidade de Queimados, zona Rural, Feira Nova- PE, Para isto, além do estudo aprofundado das técnicas acompanhou-se a aplicação de diferentes métodos de avaliação referente as perguntas que foram elaboradas pela equipe de elaboração e aplicação dos questionários. Os resultados obtidos mostraram que a comunidade apresenta deficiência na assistência técnica, mesmo assim na localidade há uma grande diversidade de plantios e culturas de subsistência, a comercialização dos produtos oriundo dos plantios e sendo comercializados através dos programas sócias do governo.

Palavras-Chave: Extensão. Desenvolvimento. Diagnóstico Rural Participativo.

\section{Introdução}

O Diagnóstico Rápido Participativo (DRP) é uma técnica que consiste em um trabalho de abordagem de uma determinada comunidade ou grupo, na qual é feito um levantamento sobre a mesma, observando os pontos que podem ser melhorados na comunidade. A importância de se gerenciar um planejamento a partir de um diagnóstico próprio da comunidade faz com que os agricultores rurais possam compartilhar suas experiências analisando as técnicas do DRP como

\footnotetext{
${ }^{1}$ Curso, Instituição, E-mail: Bacharelado em Agronomia, IFPE- Campus Vitória de Santo Antão adjairsilva.agronomia.ifpe@ gmail.com,

${ }^{2}$ Curso, Instituição, E-mail: Bacharelado em Agronomia, IFPE- Campus Vitória de Santo Antão, denisonsila@gmail.com

${ }^{3}$ Coordenador, Instituição, E-mail: Técnico em Agropecuária, IFPE- Campus Vitória de Santo Antão, ronaldo.alves@ vitoria.ifpe.edu.br,
} 
forma de buscar um melhor aproveitamento e planejamento de suas propriedades rurais (VERDEJO, 2006).

O DRP se baseia no serviço de assistência técnica e extensão rural que tem como foco a universalização do conhecimento no campo. Em que a atuação do extensionista não deve se orientar por pacotes tecnológicos prontos, pois é necessário respeitar as diversas aptidões produtivas e de serviços, apoiando a multifuncionalidade do meio rural, de modo que não se definam atividades apenas pela ótica da produção e sim sob o olhar da renda, segurança e estabilidade, que juntos encaminharão à sustentabilidade (SANTOS et al., 2010). Portanto o trabalho teve como objetivo avaliar os problemas da comunidade de Queimados, por meio do diagnostico rural rápido participativo.

\section{Fundamentação Teórica}

A falta de assistência técnica para os agricultores tem interferido ano após ano na produção e na comercialização das culturas e dos animais, pressuposto a isso o DRP entra como ferramenta de ajuda para este, sendo os dados elencados, formando uma maneira de assistência técnica e extensão rural, contribuindo assim para o desenvolvimento da comunidade, para que os agricultores possa ter qualidade de vida. Os participantes poderão compartilhar experiências e analisar os seus conhecimentos, a fim de melhorar as suas habilidades de planejamento e ação. A partir do DRP tenta-se avaliar os problemas e as oportunidades de solução, identificando os possíveis projetos de melhoria dos problemas mais destacados por grupos de pessoas de diferentes idades, posição social e política, que podem apresentar posturas semelhantes ou contrárias, e que contribuem com seus pontos de vista. (MARY et al., 2011).

Tem sido cada vez mais reconhecido, inclusive por parte dos agentes financiadores, a necessidade de conhecer a perspectiva das comunidades locais quanto aos seus principais problemas bem como sua avaliação quanto ao impacto de programas e projetos de desenvolvimento. Assim o DRP tem sido utilizado em várias áreas, dentre as quais Mikkelsen (1995) cita: projetos de preservação ambiental, pesquisa em sistemas de produção, manejo de recursos naturais, água e saneamento, destinação de lixo, saúde, educação, habitação urbana e atividades de geração de renda.

O simples uso de técnicas desenvolvidas a partir do enfoque participativo, não garante por si só a efetiva participação dos agricultores no processo de diagnóstico e proposição de medidas para relaxamento das restrições. É necessária uma mudança de postura do pesquisador na forma de encarar o agricultor. Este comportamento exige do técnico um preparo especial, uma vez que normalmente ele não está acostumado a ver no agricultor um parceiro capaz de contribuir na análise 
da realidade. Como alertam Guijt \& Cornwall (1995), "aprender o uso de técnicas é a parte mais fácil. Adquirir a habilidade de comunicação e facilitação para aplicar junto aos agricultores é o mais difícil". A ênfase exagerada na aplicação de técnicas, pura e simplesmente, tem acarretado que muitas vezes o diagnóstico participativo tenha sido utilizado para buscar fatos antes de explorar perspectivas.

\section{Metodologia}

A assistência técnica foi desenvolvida na comunidade rural de Queimados do munícipio de Feira Nova -PE distando do Instituto Federal de Pernambuco (IFPE) Campus Vitória de Santo Antão $36,7 \mathrm{~km}$. Os principais produtos agropecuários produzidos são a mandioca, batata doce, milho, feijão, inhame e criações de ovinos, caprinos e bovinos, sendo assim suas principais fontes de renda.

As dificuldades de beneficiamento e comercialização de sua produção e a falta de organização social, aliados a outros problemas, são os principais entraves ao desenvolvimento daquela comunidade. Em todas as etapas do trabalho foram adotadas metodologias participativas, protagonizando os agricultores e agricultoras neste processo coletivo de construção de conhecimentos. Foram atendidas ao todo vinte famílias que participaram de onze reuniões, uma a cada mês, nas reuniões estavam presentes quarenta agricultores, onde todos participaram assiduamente de todas as atividades e oficinas desenvolvidas. Baseando-se nos seus próprios conceitos e critérios de explicação além da aplicação dos questionários, em que os agricultores responderam individualmente as perguntas previamente formuladas, foi também proposto que os próprios participantes, em oficinas com os grupos temáticos (mulheres, jovens e idosos), analisassem a sua situação e valorizasse as diferentes opções para melhorá-la bem como para levantar questões não mensuráveis como anseios, lutas, interações e eventuais conflitos existentes.

Durante o aplicação do DRP, detectou-se alguns problemas na comunidade, como, os agricultores não terem acesso a escolaridade, falta de assistência técnica, e dificuldades em produção de hortaliças por parte dos agricultores da comunidade, quem compravam nas feiras ao invés de produzirem. Com estas demanda foram ofertadas duas oficinas de produção e construção de hortas e uma oficina de produção de biofertilizante e uma de produção de compostagem, todos eles com participação efetiva dos agricultores.

As oficinas foram realizadas pela equipe executora do projeto com o caráter multi e interdisciplinar, visto que tiveram colaboração de profissionais e docentes de setores diversos do (IFPE) Campus Vitória. Esta diversificação das atividades, e da participação de profissionais de diversos segmentos de nosso Instituto de Ensino, contribuiu para termos uma visão holística de 
nosso trabalho, uma vez acreditando no âmbito das práticas conjuntas no nosso cotidiano, que diante das demandas e necessidades, requerem que caminhemos integrados na mesma direção. Os gráficos foram gerados no programa Excel.

\section{Resultados e Discussão}

O perfil escolar da comunidade diagnosticou que $10 \%$ dos agricultores apresentam ensino médio completo, e que $30 \%$ não apresentam escolarização. 5\% apresentam-se cursando o ensino superior, esses alunos apresentam uma faixa etária entre dezenove e vinte e oito anos. (Figura 1A). Em ralação a renda familiar 55\% das famílias ganham de um a três salários mínimos (Figura 1B). Isso é um ponto positivo que mostra que os agricultores mesmo com algumas limitações e dificuldades vem alcançando uma renda mensal considerada boa, em comparação com renda média nacional que de acordo com o IBGE 2014 é de 1,5 salários mínimos

Figura 1- Perfil dos diferentes níveis de escolaridade (A) e Renda mensal das famílias (B) da comunidade de

A

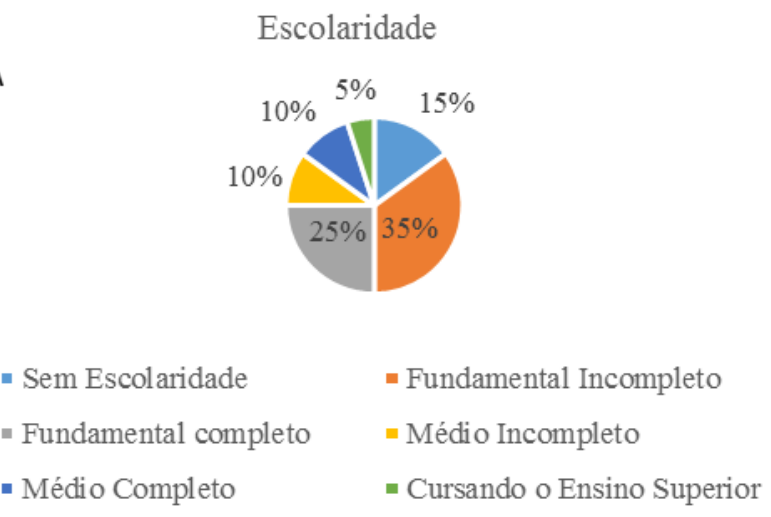

B

Renda Mensal das Familias

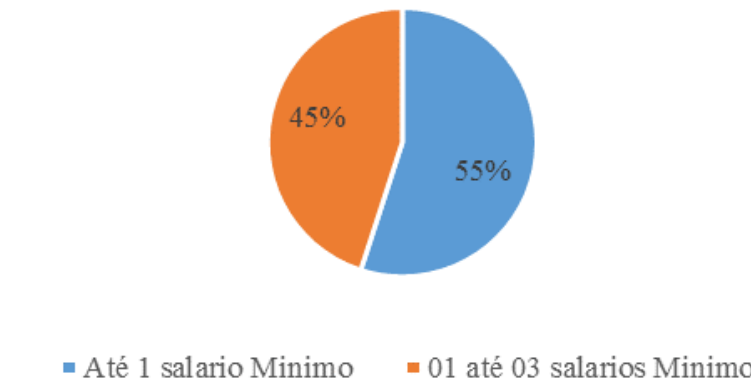

Queimados, Zona rural de Feira Nova - PE, 2016.

Em relação a comercialização dos produtos são realizadas por mio das feiras livres $50 \%$, e os 45\% vendem para programas sociais PAA (Programa de Aquisição de Alimentos), (Figura 2C) que é obrigada a comprar no mínimo 30\% da produção agropecuária proveniente da agricultura familiar. Para Buainain (2007), a comercialização se constitui como um grande desafio para a agricultura familiar.

Em relação a produção de hortaliças $65 \%$ dos agricultores compram as hortaliças nas feiras, e os demais cultivam em suas casas, (Figura 2D). Diante desse dados alarmantes a equipe do DRP ofertou oficinas de construção de hortas, oficinas de biofertilizantes e compostagem para serem utilizados na produção das hortas. Portanto, foram implantadas cinco hortas modelos com o intuído de incentivar a produção de hortaliças para consumo bem como para comercialização. 
Figura 2- Comercialização dos Produtos (C) e Produção de hortaliças (D) na comunidade de Queimados zona rural Feira Nova - PE, 2016.

C

Comercialização dos Produtos

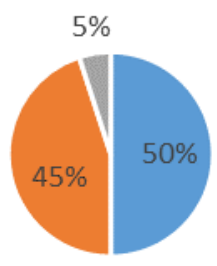

- Feiras Livres " Programas Sociais = Outros
Produção de Hortaliças

D

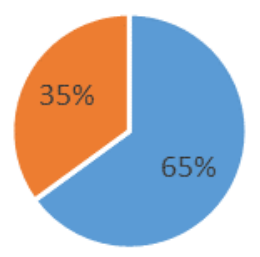

- Compram na feira $\quad$ - Produzem em casa

Entretanto a área de preservação permanente (APP) apenas 50\% das propriedades têm essa reserva (Figura 3E). E em relação as nascentes $70 \%$ das propriedade não apresenta (Figura 3F). Assim foi ofertada uma oficina demonstrando aos agricultores as importâncias da implantação e sua preservação. Com a implantação de APPs, preocupados com as partes altas da bacia. Castro e Lopes (2001) afirmam que é indispensável para a recuperação e conservação das nascentes a presença de árvores nos topos dos morros e das seções convexas, estendendo-se até 1/3 das encostas, tema devidamente regulamentado pela Resolução CONAMA, nº 303 de março de 2002.

Figura 3- Áreas de Preservação Permanente (E) e Áreas com nascentes naturais de água nas propriedades dos agricultores na comunidade de Queimados zona rural de Feira Nova - PE

Áreas de Preservação Permanente

$E$

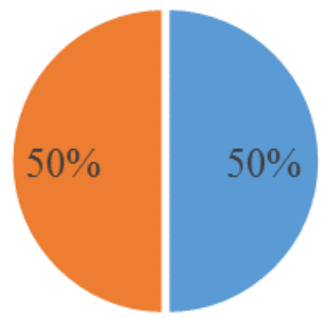

- Possuem " Não possuem
Nascentes Naturais de Agua na

$\mathrm{F}$ Propriedade

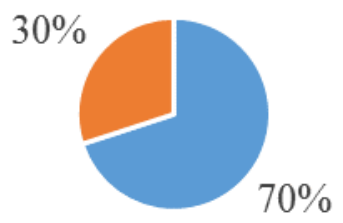

• Não Tem - Tem 
$\mathrm{O}$ fato de existirem poucas nascentes e APP é provavelmente devido à baixa assistência técnica, pois $55 \%$ dos agricultores não recebem a mesma (Figura $4 \mathrm{H}$ ). No entanto, esse direito é garantido pela lei da ATER n ${ }^{\circ} 12.188$, de 11 de janeiro de 2010.

Mesmo com algumas limitações quanto a assistência técnica, verificou-se que $95 \%$ dos agricultores não fazem uso de defensivos agrícolas em suas produções (Figura 4G).

Figura 4 - Uso de defensivos agrícolas $(G)$ e Recebimento de assistência técnica $(H)$ na comunidade de Queimados, zona rural Feira Nova - PE, 2016.
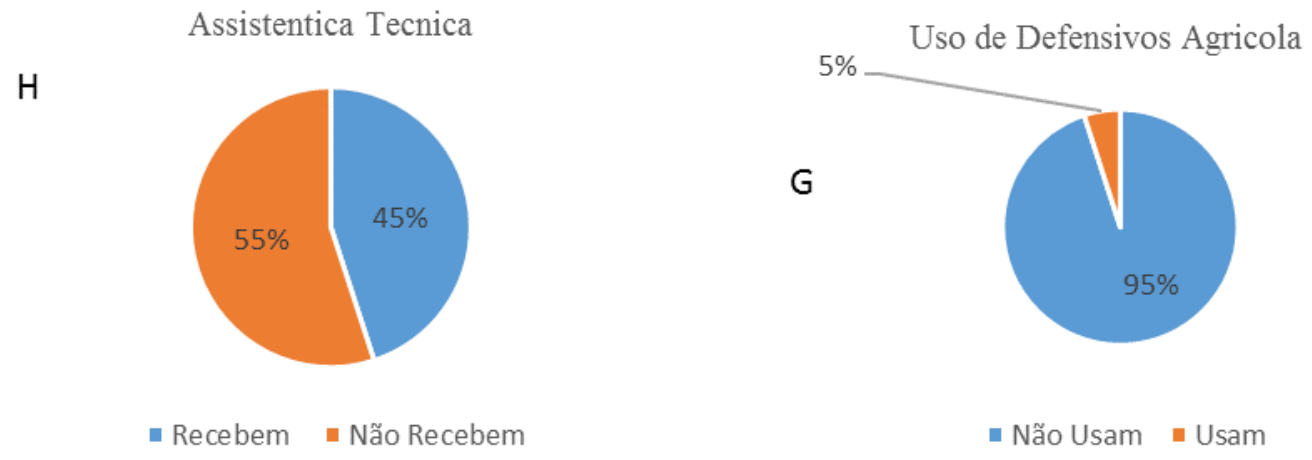

Já em relação a pecuária é uma característica bastante forte da comunidade pois $95 \%$ dos moradores criam algum tipo de animal de produção (Figura 5I). Sendo, a criação de bovinos de corte, caprinos, ovinos e aves, contribuindo na renda das famílias, bem como, o uso de esterco para a manutenção do solo, e uso nas hortas no qual cultivam suas hortaliças de forma sustentável garantindo a soberania alimentar e a qualidade de vida.

Figura 4 - Uso de defensivos agrícolas (G) e Recebimento de assistência técnica (H) na comunidade de Queimados, zona rural Feira Nova - PE, 2016.
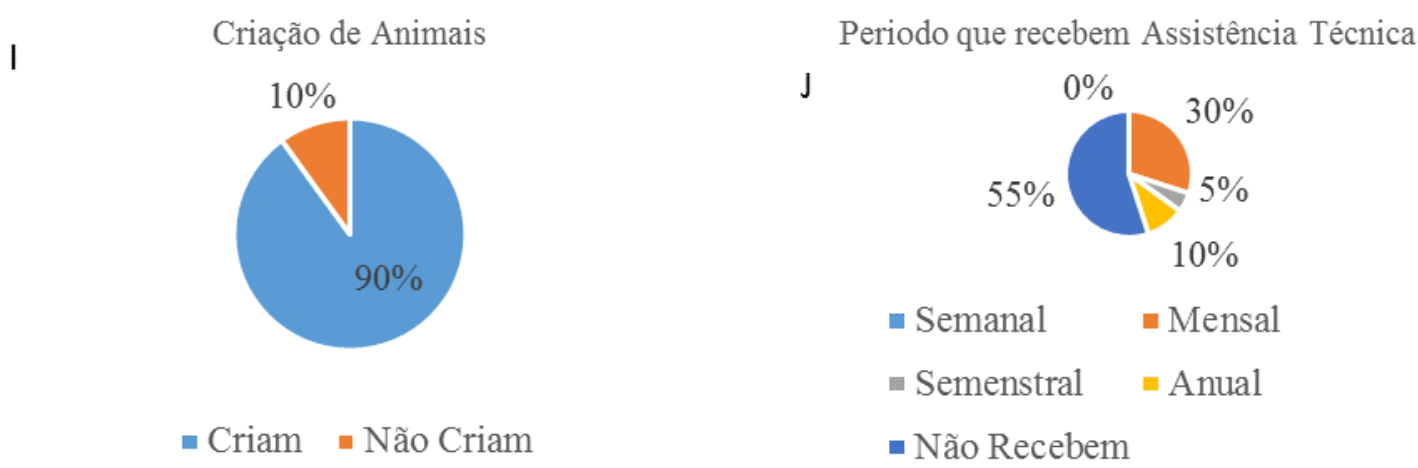
O resultados obtidos pela aplicação do DRP mostraram que a comunidade de Queimados apresenta algumas demandas referentes a assistência técnica e extensão rural, sendo que com a aplicação do DRP essa situação foi mudada de forma ampla e participativa que trouxe para todos melhor qualidade de vida.

\section{Conclusões}

O Diagnóstico Rural Participativo possibilitou repensar estratégias de extensão rural, intervenções em comunidades agrícolas, bem como planejamento de atividades voltadas ao espaço rural.

O DRP permitiu reconhecer as potencialidades endógenas do processo de análise de todo território, pois privilegiou os saberes locais dos (as) próprios (as) agricultores (as), possibilitando desta forma a formação de agentes do processo de reconhecimento territorial.

\section{Referências}

CAPORAL, FRANCISCO ROBERTO; COSTABEBER, José Antônio. Por uma nova extensão rural: fugindo da obsolescência. Rev. Reforma Agrária, Campinas: ABRA, v.24, n. 3, set/dez, 1994. (o mesmo texto pode ser encontrado na Rev. Extensão Rural, Santa Maria:

CHAMBERS, R. Rural Appraisal: Rapid, Relaxed and Participatory. London, Institute of Development Studies, 1992. (Discussion Paper 311).

GUIJT, I. \& CORNWALL, A. Editorial: Critical reflections on the practice or PRA. London, PRA Notes 24, IIED, 1995. P. 2-7.

$\begin{array}{lllll}\text { IBGE, } & \text { Censo } & \text { Demográfico } & 2010 . & \text { Disponível }\end{array}$ www.censo2010.ibge.gov.br/sinopse/.../frm_hom_mul.php? código. Acesso em 21/10/2016.

MARY, W.; ARRUDA, J.; SILVA, V.; DUTRA, P.; SOUZA, R. S. Oficina de diagnóstico rural participativa. C I Orgânicos. Centro de inteligência. Rio de Janeiro, 2011. 
MIKKELSEN, B. Methods for Development Work and Research: A Guide for Practitioners. New Delhi, Sage, 1995. 290 p.

PRETTY, J. N. and VODOUCHÊ, S. D. (1997): “Using Rapid or Participatory Rural Appraisal”. en: SWANSON, B. E.; BENTZ, R. P. and SOFRANKO, A. J. (eds.) (1997): Improving Agricultural Extension: A Reference Manual. Roma: FAO. pp. 47-55.

PRETTY, J.; GUIJT, I.; THOMPSON, J. \& SCOONES, I. Participatory Learning \& Action: A Trainer's Guide. London, IIED, 1995. 267 p.

VERDEJO, M.E. Diagnóstico rural participativo - Guia Prático DRP. Brasília: MDA/SAF/DATER, 2006. Disponível em: http://www.mda.gov.br/sitemda/sites/sitemda/files/user_arquivos_64/Guia_DRP_Parte_1.pdf: Acesso em 02/09/2016. 